\title{
Prioritising elective care: a cost utility analysis of orthopaedics in the north west of England
}

\author{
Marilyn James, Selwyn St Leger, Kathleen V Rowsell
}

\begin{abstract}
Study objective - To produce a priority list for purchasers to use when purchasing elective care in the speciality of orthopaedics so that efficiency in health care purchasing (that is, maximising the benefit per unit of resource available for the resident population) can be achieved.
\end{abstract}

Design - The study used cost utility analysis in the elective speciality of orthopaedics. The diagnostic groups in the study were chosen on the basis of those conditions that constituted the greatest proportion of the orthopaedic waiting list, and consequently the greatest proportion of activity within the speciality. Costs were derived by two methods: the extra contractual referral tariff (ECR) and individual patient based costings. Outcome was assessed before surgery and again approximately six months afterwards. The outcome of the procedures was derived in two ways: Rosser and EuroQol indices.

Setting - The study took place at Wrightington hospital, a specialist orthopaedic hospital in north west England.

Patients - Prospective assessments were obtained from 99 patients for nine orthopaedics procedures. All the patients were individually interviewed on each occasion. Rosser and EuroQol assessments were completed for each patient by the patient and the patient's consultant before and after surgery.

Main results-Priority lists presenting cost utility rankings for each of the procedures were derived from the patients' and consultants' assessments.

Conclusions - It is feasible to generate priority lists in a systematic way. Purchasers may then use the results from these priority lists to help them maximise the benefits per unit of resource for their resident population.

( $($ Epidemiol Community Health 1996;50:182-189)

To function effectively in the market, commissioners of health services (purchasers) must be able to make clear and explicit decisions about the goods and services they purchase in order to achieve the "best" possible health care package for their resident population - that is, to maximise efficiency in purchasing. The "new public health" function in purchasing has a role to play in this process which requires prioritisation between competing services or pro- cedures. To do this purchasers need access to information on a range of outcomes, the quality of these outcomes, and about costs - that is, cost benefit information.

The work reported here took place in West Lancashire Health Authority in the north west of England from 1990-92. It develops the application of cost utility analysis to a range of orthopaedic procedures. The published reports on outcome assessment in orthopaedics are clinically dominated and contain very little on the patients' functional and psychological assessment of outcome. ${ }^{1-5}$ The use of health status measurement, and specifically the application of the quality adjusted life year, will extend the purchaser's information set and should facilitate improved decision making.

The quality adjusted life year (QALY) measures the quality and the quantity of life. Hence, the QALY is calculated by multiplying the quality indicator (index value) by the quantity indicator (years of life). Benefit measured by QALY is expressed in terms of a composite numerical index between 0 and 1 , where 1 is equivalent to one year in perfect health and 0 is dead or unconscious. The QALY, or index measures in particular, can draw many different aspects of quality of life such as pain and mobility into a common index. Cost utility analysis expresses the benefits and cost of the procedures studied in terms of cost per QALY gained from undertaking each of the procedures. The alternative to an index would be the use of a profile. This can often provide baseline data only, however, that can be highly influenced by external factors. It does not collapse the various dimension of health into a single unit of benefit and faces the decision maker with the dilemma of rating the relative importance of each dimension. This study focuses upon the use of index values.

The study used two index measures to determine health status or benefit after surgery: the Rosser classification of illness states and the EuroQol.

The Rosser classification of illness states ${ }^{6}$ provides pairwise groupings of four distress and eight disability states experienced by the patient that can be converted into a composite numerical index. The index parameters operate between 0 and 1 , where 0 represents dead and 1 represents one year of perfectly healthy life. The original tariff values were used making it possible to be in a state worse than death, which is represented by a negative score. Gudex and $\mathrm{Kind}^{7}$ provide a detailed exposition of the use of this index. 


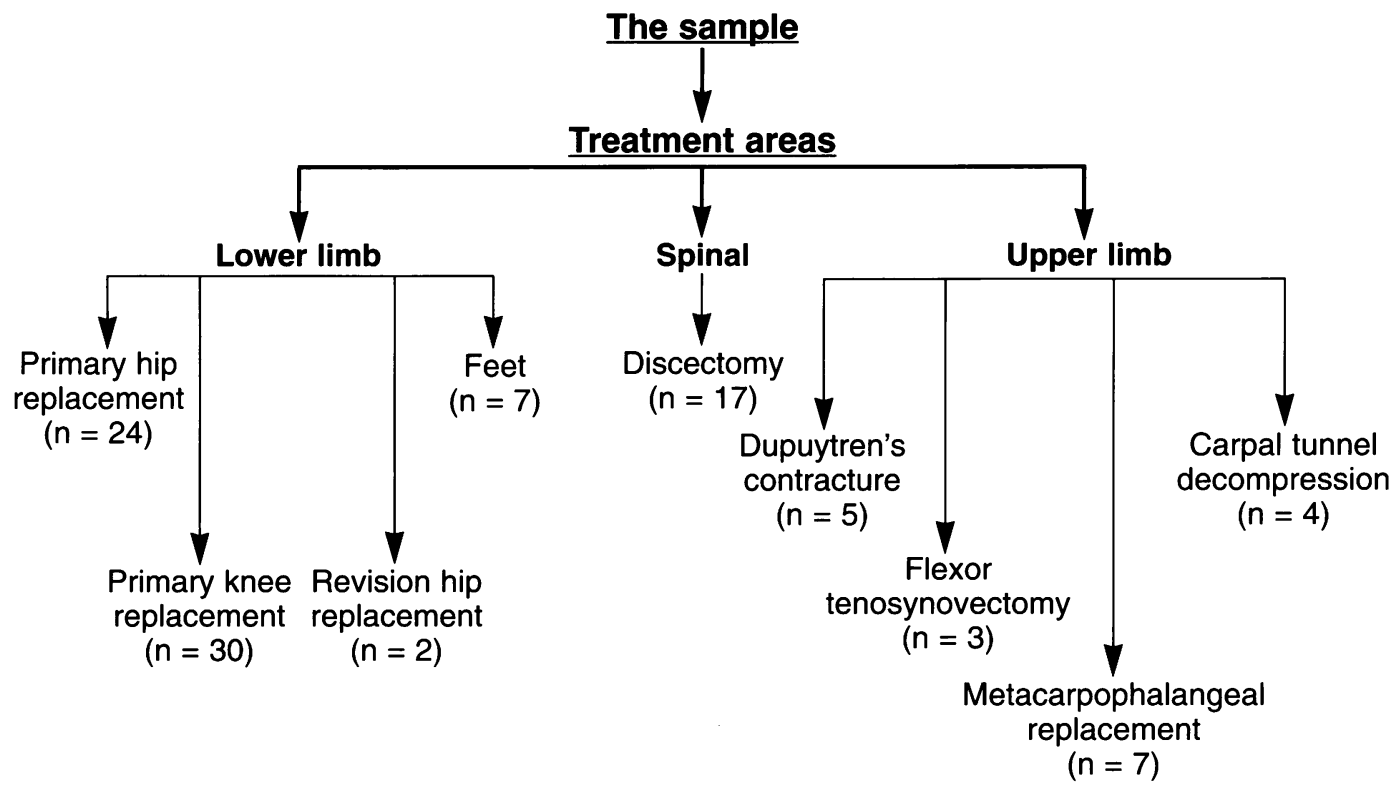

The study population.

The EuroQol ${ }^{8}$ is a new classification that includes additional aspects of health. There are five dimensions of health each with a 1 (best health) to 3 (worst health) rating. These are mobility, self care, usual activities, pain/discomfort, and anxiety/depression. The five states convert into a composite numerical index between 0 and 1 , where 1 represents perfect health and 0 is dead or unconscious. The tariff used was the original one from Frome, Somerset.

Orthopaedic surgery was chosen as the speciality with which to explore prioritisation because it has a set of discrete procedures each with relatively clear indications for their use and each leading to potential benefits which could be assessed after a relatively short time. Elective orthopaedics has notoriously long waiting times ${ }^{9}$ and is believed to be one of the major elective areas where substantial health gains may be made. Hence we intended to extend both practically and theoretically the work began by Gudex et $a l^{10}$ in general surgery.

\section{Method}

The study population comprised all patients under the care of each of the participating orthopaedic surgeons at a single speciality orthopaedic hospital between May and August 1991 for one of the nine procedures shown in the figure and detailed in appendix I. The study was explained to the patients in writing and verbally before obtaining their informed consent. The patients were assessed preoperatively and six months postdischarge by which time the full benefits of surgery should have been realised. Patients were sent up to three follow up appointments. Those who failed to attend were sent copies of the assessment forms by post. If these were not returned, up to three attempted telephoned contacts were made.
The nine procedures were those that constituted the greatest proportion of the orthopaedic waiting list, and furthermore the greatest proportion of the activity within the speciality. The patients' conditions were chronic with little change in health status expected without surgical intervention. The procedures undertaken affect quality of life rather than life expectancy. Because the procedures used are well established as technically successful it was not necessary, or indeed ethically acceptable, to undertake a randomised controlled trial. Hence the "before and after" study design.

In addition to assessments of the patients' health states by the researcher (MJ), independent assessments were undertaken by each patient's consultant.

The patients completed, unaided, the EuroQol self reported health states ${ }^{8}$ before and after surgery, these were then converted into a single health status index number using the tariff provided by the York EuroQol team using valuations of health states obtained from a population in Frome, Somerset (personal communication Gudex). A similar approach was taken to the administration of the Rosser health status classification, although patients did require occasional assistance. In addition, general questions were asked regarding the duration of illness, quality of life over time, comorbidities, and any subsequent complications.

Costs were attached to all the procedures in the analysis. These were calculated by two different approaches: extra contractual referral tariff (ECR) and patient based individually derived costs, the latter undertaken by detailed data extraction from the case notes. The ECR tariff reflects the market price of the good, in this case the average price for a procedure as a proportion of the total budget within orthopaedics. It may be used as a first point of 
reference by purchasers when making purchasing decisions. The patient based costs were obtained in order to provide a marginal cost for each procedure and as a validity check upon the ECR average cost. This meant that a detailed ingredient cost for each procedure was required. In brief, this included information on drug usage, pathology/haematology tests, $x$ rays, aids and appliances, length of stay, and readmissions, obtained from trawling the case notes and checking the theatre record to obtain operative costs. This information was, where possible, cross checked against the centralized hospital information systems.

The costs for each procedure, however calculated, reflect not just the primary operative code but all associated tests - for example, $x$ ray procedures and outpatient appointments. For hip replacements, two separate costs were used to allow for variations in the patients' ages; those under 40 years have a more durable and expensive prosthesis implanted.

The costing process at Wrightington was sufficiently sophisticated, such that the ECR tariff and patient costs were indeed similar. Henceforth the findings of the study are reported using the patient based costs.

Costs and benefits do not remain constant, and it is the stream of costs and benefits over time that are important for cost utility analysis and cost per QALY calculations (see the report by Williams ${ }^{11}$ on multiple sclerosis). In this analysis factors taken into consideration were as follows: the patients' life span and, where appropriate, length of life of the prosthesis; the probability of complications (derived from the consultants' own data and the published reports; the probability of failure (included in the calculations by percentage that benefit); and the decay point, that is the point in time from which the prosthesis starts to decay, and decay rate of benefit over time. The net gain in quality of life is therefore calculated by subtracting the initial health state valuation from the final, multiplied by the years of remaining life and subject to the adjustments factors detailed above (see appendix II). Costs in orthopaedic surgery occur primarily during the hospital inpatient stay, or within the first six months out of patient follow up; hence discounting future costs is largely unnecessary except for the probability of revision surgery. Where appropriate costs were discounted using the recommended treasury rate of $6 \%$.

Sensitivity analyses were performed to test the robustness of the resulting cost utility rankings. These included altering the costs of the prosthesis, the estimates concerning the expected life of the prosthesis, and scenarios where patient outcome reflected the best quality of life improvement from the patients' experiences.

\section{Results}

Table 1 shows the pre-operative and postoperative completion rates of the quality of life assessments. Ninety nine patient outcome assessments were obtained.
The values and ranges of the patients' and consultants' assessments of the patients' health status before and after surgery are presented in tables 2 and 3. This is calculated for each individual patient using the response to the health status questionnaire and inputing the health valuation tariff value, as described earlier, for both the Rosser and the EuroQol health status assessment questionnaires. These index values are then used throughout to calculate the QALYs per patient per procedure. It should be stressed that as with any range the potential difference is broad, and attainment of a "perfect" health status of 1 is subject to the limitations and sensitivities of the health status assessment measures.

No statistically significant difference was found between either the patient or the consultant preoperative assessments, by either the Rosser or EuroQol measures. A statistically significant difference $(p<0.001)$ was found postoperatively for both the Rosser and EuroQol assessments. In both cases, the consultants rated the outcome higher than did the patients. In the overall improvement scores, no statistically significant difference between patient and consultant ratings was found for the Rosser assessments, however, a significant difference was found for the EuroQol assessments.

Breakdown of this difference by operative procedure showed that for spinal surgery, foot surgery, revision hip surgery, Dupuytren's contracture, flexor tenosynovectomy, and carpal tunnel syndrome, there were no statistically significant differences between the consultants' and patients' ratings either preoperatively, postoperatively, or in overall improvement using either a Rosser or EuroQol assessment. In both primary hip replacement and primary knee replacement clinicians rated final outcome markedly higher than patients; with the EuroQol valuations metacarpophalangeal joint replacement was also rated higher by clinicians. In only two instances were improvement statistically significantly different by procedure between patients and consultants - knee replacements and metacaropophalangeal joint replacement assessed by the EuroQol tool.

Tables 4 and 5 respectively show the Rosser QALY and EuroQol net gains in quality of life (final-initial health state valuation, by life span (adjusted)), alongside costs and costs per QALY. The first column shows the health state valuation obtained from the patients' assessment of their health status. The second column is the consultants' perceived assessment of the individual patients' health status before and after surgery. This is recorded after assessing the patient and does not reflect a hypothetical valuation for an average patient. Cost remains constant whether patient or consultant health status valuations are used. The final two columns represent cost divided by QALY (patient and consultant respectively); this places costs and QALYs into a common ground and shows for each procedure how much must be spent to gain an additional QALY per person. Hence the smaller the figure in this final column, the more cost effective the procedure. To illustrate this from table 2 using 
Table 1 Percentage completion for the studies

\begin{tabular}{|c|c|c|c|c|c|}
\hline \multirow[t]{3}{*}{ Study } & \multirow{3}{*}{$\begin{array}{l}\text { Sample } \\
\text { size }\end{array}$} & \multicolumn{4}{|c|}{ Assessment tool } \\
\hline & & \multicolumn{2}{|c|}{ Rosser $Q A L Y$} & \multicolumn{2}{|c|}{ EuroQol } \\
\hline & & Patient & Consultant & Patient & Consultant \\
\hline $\begin{array}{l}\text { General prospective (preopeative) } \\
\text { General prospective (postoperative) }\end{array}$ & $\begin{array}{l}99 \\
99\end{array}$ & $\begin{array}{r}100 \\
92\end{array}$ & $\begin{array}{l}84 \\
84\end{array}$ & $\begin{array}{r}100 \\
92\end{array}$ & $\begin{array}{l}81 \\
81\end{array}$ \\
\hline
\end{tabular}

consultant health status valuations, it costs $£ 868$ to generate an additional QALY performing a spinal discectomy and $£ 330$ for a carpal tunnel. Hence a carpal tunnel operation generates more QALYs per unit of cost than a spinal discectomy.

Table 6 presents a summary of the results ranked in order of greatest benefit and also ranked in ascending order of cost per QALY.

For all the procedures the final health status valuation was statistically significantly different $(\mathrm{p}<0.001$, Wilcoxon matched pairs) from the original health status measure, hence both quality measures were sensitive to measure change in patient quality of life. Moreover, it was encouraging that related aspects of quality of life, for example, mobility and pain, described in both health status instruments consistently moved in the same direction when analysed as individual dimensions of health or functional well being. In terms of external validity those subsets of the Rosser and EuroQol assessment that one would be expected to be correlated, for example, mobility and pain, were indeed correlated.

The priority lists (table 6) constructed from patient responses and consultant responses are similar with respect to benefits alone (patient Rosser compared with consultant Rosser and patient EuroQol compared with consultant EuroQol) and cost per QALY. However, there were some noticeable discrepancies. These were most evident in the placing of foot operations, metacarpophalangeal joint replacement and, in absolute difference, between the clinician and patent valuations of spinal discectomy. It should be noted that for procedures the number in the sample is small,

Table 2 Rosser health state valuations in relation to procedure

\begin{tabular}{|c|c|c|c|c|c|c|c|c|c|c|}
\hline \multirow[t]{2}{*}{ Procedure } & \multirow{2}{*}{$\begin{array}{l}\text { Sample } \\
\text { size }\end{array}$} & \multicolumn{3}{|c|}{ Preoperative } & \multicolumn{3}{|c|}{ Postoperative } & \multicolumn{3}{|c|}{ Improvement } \\
\hline & & Mean & Minimum & Maximum & Mean & Minimum & Maximum & Mean & Minimum & Maximum \\
\hline$(1)^{*}$ Spine discectomy & 17 & $0 \cdot 812$ & $0 \cdot 000$ & 0.973 & 0.949 & $0 \cdot 800$ & 1.000 & $0 \cdot 146$ & -0.050 & 0.995 \\
\hline$(2)^{*}$ & & $0 \cdot 891$ & 0.085 & $0 \cdot 680$ & 0.964 & 0.900 & $1 \cdot 000$ & 0.071 & 0.000 & $0 \cdot 310$ \\
\hline (1) Primary hip replacement & 24 & 0.892 & 0.700 & 0.988 & 0.976 & 0.900 & $1 \cdot 000$ & 0.084 & 0.000 & $0 \cdot 300$ \\
\hline (2) & & $0 \cdot 897$ & 0.700 & 0.965 & 0.989 & 0.946 & $1 \cdot 000$ & 0.092 & 0.030 & $0 \cdot 300$ \\
\hline (1) Primary knee replacement & 30 & $0 \cdot 868$ & 0.700 & 0.973 & 0.932 & 0.000 & $1 \cdot 000$ & $0 \cdot 044$ & $-0 \cdot 900$ & $0 \cdot 272$ \\
\hline (2) & & 0.905 & 0.700 & 0.972 & 0.975 & $0 \cdot 785$ & $1 \cdot 000$ & 0.069 & -0.136 & $0 \cdot 300$ \\
\hline (1) Feet & 7 & 0.939 & $0 \cdot 700$ & 0.986 & 0.917 & $0 \cdot 700$ & 1.986 & -0.006 & -0.016 & 0.001 \\
\hline (2) & & $0 \cdot 905$ & 0.564 & 0.986 & 0.976 & 0.942 & $1 \cdot 000$ & 0.014 & -0.029 & $0 \cdot 100$ \\
\hline (1) Revision hip replacement & 2 & $0 \cdot 800$ & $0 \cdot 700$ & 0.900 & 0.976 & 0.972 & 0.980 & $0 \cdot 176$ & $0 \cdot 080$ & $0 \cdot 272$ \\
\hline $\begin{array}{l}\text { (2) Metacarpophalangeal } \\
\text { (1) Men }\end{array}$ & & $0 \cdot 900$ & 0.900 & $0 \cdot 900$ & 0.979 & 0.972 & 0.972 & 0.079 & 0.072 & 0.086 \\
\hline joint replacement & 7 & $0 \cdot 918$ & $0 \cdot 870$ & $0 \cdot 956$ & 0.954 & 0.942 & 0.972 & 0.036 & 0.014 & 0.072 \\
\hline (2) & & $0 \cdot 878$ & $0 \cdot 700$ & 0.960 & 0.975 & 0.900 & 0.993 & 0.098 & 0.000 & $0 \cdot 290$ \\
\hline (1) Dupuytren's & 5 & 0.981 & 0.972 & 0.986 & 0.994 & 0.990 & $1 \cdot 000$ & 0.013 & 0.004 & 0.028 \\
\hline (2) & & 0.989 & 0.986 & 0.995 & $0 \cdot 996$ & 0.995 & 1.000 & 0.007 & 0.000 & 0.014 \\
\hline (1) Flexor tenosynovectomy & 3 & 0.846 & $0 \cdot 700$ & 0.932 & $0 \cdot 881$ & $0 \cdot 680$ & 0.986 & 0.035 & -0.020 & 0.080 \\
\hline (2) & & 0.933 & 0.900 & 0.956 & 0.971 & 0.956 & 0.986 & 0.039 & 0.014 & 0.072 \\
\hline (1) Carpal tunnel & 4 & $0 \cdot 951$ & 0.935 & 0.956 & $0 \cdot 964$ & 0.935 & 0.986 & 0.015 & 0.000 & 0.030 \\
\hline (2) & & 0.979 & 0.956 & 0.995 & 0.993 & 0.986 & $1 \cdot 000$ & 0.014 & -0.009 & 0.044 \\
\hline
\end{tabular}

*(1) Represents patients' values and (2) represents consultants' values.

Table 3 EuroQol health state valuations by procedure

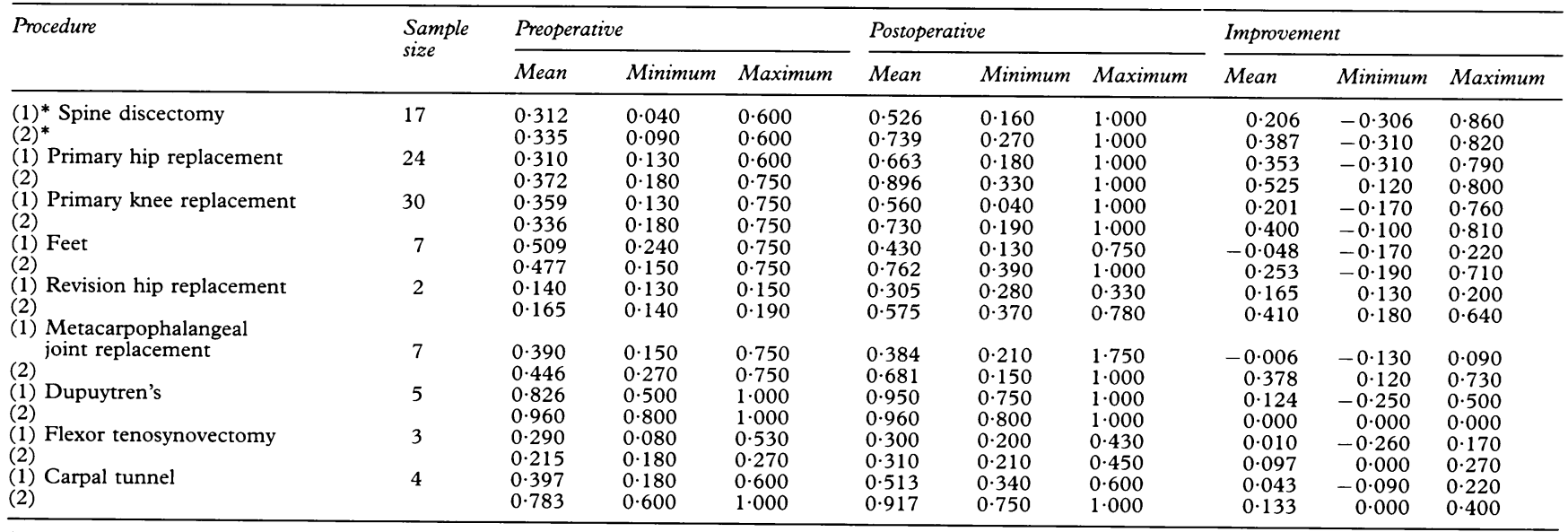

*(1) Represents patients' values; (2) represents consultants' values. 
Table 4 Net health gain using the Rosser index with patient and consultant valuations, patient based costs, and cost utility ratios in $£ s$

\begin{tabular}{|c|c|c|c|c|c|}
\hline \multirow[t]{2}{*}{ Operation } & \multicolumn{2}{|c|}{ Net health gain } & \multirow[t]{2}{*}{ Cost $(£)$} & \multicolumn{2}{|c|}{ Cost per $Q A L Y(£)$} \\
\hline & $\begin{array}{l}\text { Patient } \\
\text { valuations }\end{array}$ & $\begin{array}{l}\text { Consultant } \\
\text { valuations }\end{array}$ & & Patient & Consultant \\
\hline Spinal discectomy & $4 \cdot 841$ & $2 \cdot 534$ & 2044 & 422 & 868 \\
\hline Revision, hip & $1 \cdot 762$ & 0.791 & 5078 & 2881 & 6419 \\
\hline Primary hip, age $>=40 y$ & 1.496 & 1.639 & 3112 & 2080 & 1899 \\
\hline Metacarpophalangeal & 0.799 & $2 \cdot 174$ & 2910 & 3644 & 1339 \\
\hline Primary hip, age $<40$ y & $0 \cdot 783$ & 8.019 & 3546 & 4528 & 442 \\
\hline Flexor tenosynovectomy & 0.666 & $0 \cdot 743$ & 2032 & 3049 & 2736 \\
\hline Primary knee & 0.647 & 1.014 & 4134 & 6392 & 4076 \\
\hline Carpal tunnel & 0.457 & 0.426 & 132 & 290 & 310 \\
\hline Dupuytren's & $0 \cdot 132$ & 0.071 & 708 & 5350 & 9935 \\
\hline Feet general & -0.172 & 0.401 & 1679 & -9761 & 4183 \\
\hline
\end{tabular}

Primary hips $<40 \mathrm{y}$ and $>=40 \mathrm{y}$ are those patients aged under $40 \mathrm{y}$ and $40 \mathrm{y}$ or above respectively.

Revisions $\times \%$ of expected revisions are discounted by five years.

Table 5 Net health gain using the EuroQol index with patient and consultant valuations, patient based costs, and cost utility ratios in $f s$

\begin{tabular}{|c|c|c|c|c|c|}
\hline \multirow[t]{2}{*}{ Operation } & \multicolumn{2}{|c|}{ Net health gain } & \multirow[t]{2}{*}{ Cost $(£)$} & \multicolumn{2}{|c|}{ Cost per $Q A L Y(£)$} \\
\hline & $\begin{array}{l}\text { Patient } \\
\text { valuations }\end{array}$ & $\begin{array}{l}\text { Consultant } \\
\text { valuations }\end{array}$ & & Patient & Consultant \\
\hline Spinal discectomy & $6 \cdot 830$ & $12 \cdot 831$ & 2044 & 299 & 159 \\
\hline Primary, hip $>=40 y$ & $6 \cdot 270$ & $9 \cdot 351$ & 3112 & 496 & 333 \\
\hline Primary, hip $<40$ y & $6 \cdot 108$ & $3 \cdot 759$ & 3546 & 580 & 943 \\
\hline Primary knee & 2.955 & $5 \cdot 880$ & 4134 & 1399 & 703 \\
\hline Revision, hip & $1 \cdot 652$ & $4 \cdot 105$ & 5078 & 3074 & 1237 \\
\hline Carpal tunnel & 1.309 & 4.050 & 132 & 101 & 33 \\
\hline Dupuytren's & $1 \cdot 262$ & 0.000 & 708 & 561 & N/A \\
\hline Flexor tenosynovectomy & 0.190 & $1 \cdot 847$ & 2032 & 10672 & 1100 \\
\hline Metacarpophalangeal & -0.133 & 1.997 & 2910 & -21864 & 1458 \\
\hline Feet general & $-1 \cdot 377$ & $7 \cdot 256$ & 1679 & -1220 & 231 \\
\hline
\end{tabular}

Primary hips $<40 \mathrm{y}$ and $>=40 \mathrm{y}$ are those patients aged under $40 \mathrm{y}$ and $40 \mathrm{y}$ or above respectively.

N/A $=$ not applicable.

Revisions $\times \%$ of ecpected revisions are discounted by five years.

however, there is no reason to suppose that the patient characteristics within these groups were unrepresentative of the population group for the procedure.

\section{SENSITIVITY ANALYSIS}

The results from the sensitivity analysis showed that only when total resource costs for both hips and knees were lowered by $50 \%$, did they rank higher than all the upper limb procedures, with the exception of carpal tunnel. When the prosthesis was assumed to last for more than 15 years, only at an additional eight years life did primary knee replacement rise to rank above Dupuytren's contracture. Altering the priority list to reflect best case scenarios (best recorded quality of life gain for the sample set) revealed the most changes. With the exception of revision hip operations and primary hip replacements for the under $40 \mathrm{~s}$, all the primary hip and knee replacements ranked higher in terms of least cost per QALY than the small hand operations (with the exception of carpal tunnel). In addition, the position for spinal surgery (discectomy) and carpal tunnel were reversed with spine discectomy rising one place.

DISCUSSION

This study indicates that the cost utility analysis (CUA) approach seems to be feasible in providing a framework that will assist purchasers in making health care decisions. Obtaining data on both outcomes and costs proved relatively straightforward and there was good completion of data overall. We believe further prospective studies could be conducted in this manner and will, in fact, be less time consuming and more accurate than a retrospective approach (which we piloted, but do not report on here).

The measure of outcome or benefit used in the study should depend on the objectives of the study. To compare a large number of disparate treatments and conditions requires a common

Table 6 Summary of the Rosser and EuroQol health gain and cost utility rankings, ranked by order of greatest health gain and least cost per QALY using patient derived costs

\begin{tabular}{|c|c|c|c|c|c|c|c|c|}
\hline \multirow[t]{2}{*}{ Rank } & \multicolumn{2}{|l|}{$\begin{array}{l}\text { Health gain, } \\
\text { Rosser }\end{array}$} & \multicolumn{2}{|l|}{$\begin{array}{l}\text { Health gain, } \\
\text { Euro Qol }\end{array}$} & \multicolumn{2}{|l|}{$\begin{array}{l}\text { Cost utility ratio, } \\
\text { Rosser }\end{array}$} & \multicolumn{2}{|l|}{$\begin{array}{l}\text { Cost utility ratio, } \\
\text { EuroQol }\end{array}$} \\
\hline & Patient & Consultant & Patient & Consultant & Patient & Consultant & Patient & Consultant \\
\hline 1 & Discectomy & Primary, hip $<40 \mathrm{y}$ & Discectomy & Discectomy & Carpal tunnel & Carpal tunnel & Carpal tunnel & Carpal tunnel \\
\hline 2 & Revision hip & Discectomy & Primary hip $>=40 y$ & Primary hip $>=40 y$ & Discectomy & Primary hip $<40 y$ & Discectomy & Discectomy \\
\hline 3 & Primary hip $>=40 y$ & Metacarpophalangeal & Primary hip $<40$ y & Feet general & Primary hip $>=40 y$ & Discectomy & Primary hip $>=40 y$ & Feet general \\
\hline 4 & Metacarpophalangeal & Primary hip $>=40 y$ & Primary knee & Primary knee & Revision hip & Metacarpophalangeal & Dupuytren's & Primary hip $>=40 y$ \\
\hline 5 & Primary hip $<40$ y & Primary knee & Revision hip & Revision hip & Flexor & Primary hip $>=40 y$ & Primary hip $<40$ y & Primary knee \\
\hline 6 & Flexor & Revision hip & Carpal tunnel & Carpal tunnel & Metacarpophalangeal & Flexor & Primary knee & Primary hip $<40$ y \\
\hline 7 & Primary knee & Flexor & Dupuytren's & Primary hip $<40 y$ & Primary hip $<40$ y & Primary knee & Revision hip & Flexor \\
\hline 8 & Carpal tunnel & Carpal tunnel & Flexor & Metacarpophalangeal & Dupuytren's & Feet general & Flexor & Revision hip \\
\hline 9 & Dupuytren's & Feet general & Metacarpophalangeal & Flexor & Primary knee & Revision hip & Feet general & Metacarpophalangeal \\
\hline 10 & Feet general & Dupuytren's & Feet general & Dupuytren's & Feet general & Dupuytren's & Metacarpophalangeal & Dupuytren's \\
\hline
\end{tabular}


Table 7 Rankings by major, intermediate, and minor operations using the Rosser cost utility ratios, for patient valuations

\begin{tabular}{llll}
\hline Rank & Major & Intermediate & Minor \\
\hline 1 & Primary hip $>=40 \mathrm{y}$ & Discectomy & Carpal tunnel \\
2 & Revision hip & Flexor tenosynovectomy & Dupuytren's \\
3 & Primary hip $<40 \mathrm{y}$ & Metacarpophalangeal & \\
4 & Primary knee & Feet general & \\
\hline
\end{tabular}

Primary hips $<40 \mathrm{y}$ and $>=40 \mathrm{y}$ are those patients aged under $40 \mathrm{y}$ and $40 \mathrm{y}$ and above respectively.

simple and comparable unit of benefit. Index measures permit the comparison of differing dimensions of health by converting the dimensions into a single health state valuation, hence allowing treatments to be ranked within, and between specialities.

We cannot draw firm conclusions about the comparative worth of the Rosser and EuroQol tools. The EuroQol is being tested on a much broader sample set, ${ }^{12-16}$ than that for which the Rosser original matrix, with its 70 respondents, was tested. ${ }^{17}$ Both instruments measured significant change between preoperative and postoperative scores. The Rosser tool was marginally more reliable than the EuroQol tool - externally on a test re-test basis and internally between patient and consultant valuations.

There was no marked difference between patients and doctors in the Rosser or EuroQol preoperative outcome assessments; when faced with a relatively severe position of ill health they tended to agree. In terms of overall improvement, there was no clear difference in the ratings as judged by the Rosser instrument, but there was a difference as judged by the EuroQol. This may reflect the fact that the EuroQol instrument encompasses subjective aspects of health such as anxiety and others that require personal knowledge of the patients activities. This latter may be illustrated by reference to correcting Dupuytren's contracture which was rated lower by the consultants perhaps because they were unaware of the contribution such a simple operation makes for the patient leading a fulfilling life.

The costs considered in this study are those that affect the hospital sector. Use of such costs can be justified in as much as it is these costs that purchasers will immediately be interested in when making their purchasing decisions and setting their priorities. A full economic appraisal of a procedure would take a broader view of the costs as they effect society, the economy, and the patient. The broader costs to society are a factor that a decision maker may wish to consider separately.

We have already noted that the patient based costing and prices from the ECR tariffs were negligibly different, thus highlighting the accuracy of Wrightington's accounting process. Costs in other general hospitals may bear no relationship to their quoted ECR tariff prices at the time of the study. General hospitals have the added necessity of firstly breaking down cost to specialty level before they can be disaggregated to procedure level, hence there is greater scope for error and the use of average costs across groups of procedures. Nevertheless, under market forces hospital cost procedures will become increasingly sophisticated and the ECR tariff prices more accurate. Also, use of tariff prices depends on the hospital costs being true costs and not hiding within the tariff elements of cross subsidisation between procedures.

The most important application of index measures is in their ability to provide cost utility ratios and hence rankings for treatments. Consideration of some of the general rankings of procedures within this study raises interesting points. The high cost, high publicity operations such as hip and knee replacements do not necessarily rank highest in the list either in terms of their cost utility ratios or in terms of benefit alone.

The results for upper limb surgery are intriguing. By patient and consultant measures of benefit alone upper limb surgery is ranked towards the bottom of the list (although not always below lower limb surgery). When the cost per QALY rankings are derived, the position changes appreciably especially for carpal tunnel syndrome. This operation produces a very small benefit, but for a long period of time, for very little cost, with negligible chance of recurrence; hence in terms of cost per QALY it is ranked as the number one procedure. That the benefits of upper limb surgery are substantial, for example, by enabling the patient to lead a normal life through such everyday tasks as the use of a knife and fork, is clear from our analysis; they appear to be greater than those accrued from a hip or knee replacement.

Another issue is that of aggregation of benefits and whether large but expensive benefits such as those yielded by hip replacements can justifiably be compared with operations yielding only a small benefit at low cost, for example, carpal tunnel repair. This was a similar problem to that faced by the state of Oregon ${ }^{18}$ when choosing between tooth capping and appendectomy.

Priority lists could be expressed in a variety of combinations. These may include cost per QALY bands, diagnostic category, or grouping by major, intermediate, and minor operations (table 7). Purchasers may find it useful ro rank the groups themselves (as in Oregon ${ }^{19}$ ) into order of priority and then to rank procedures within the groups. Hence, for example, it follows from table 7 that carpal tunnel would be rated at the top of the minor group, but not higher than hip replacement surgery.

Despite their attractions prioritisation tools should be used cautiously and the users of such tools, whether purchasing consortia or the patient themselves, should be aware of the rationale, origins, and the reliability of any cost utility lists. In particular, purchasers should be aware of the potential pitfalls in using "off the peg" priority lists to assist their purchasing decisions. The explicitness in prioritisation is one of the greatest advantages of priority lists. Such lists are open for all to challenge, accept, disagree with, or use. ${ }^{20}$ The work reported here could be extended to allow purchasers to derive a priority list for health care funds across the whole of elective surgery. 


\section{Appendix I}

DESCRIPTION OF THE PROCEDURES IN THE

STUDY

- Primary hip replacement

This involves replacement of the hip joint. Mobility before surgery becomes increasingly difficult and painful for the patient.

- Revision hip replacement

This involves replacement of a prosthetic hip joint, after a primary hip replacement has already occurred. The surrounding bone in a revision hip replacement has often deteriorated more than in a primary hip replacement. It is therefore a more difficult and costly operation than a primary hip replacement. The symptoms are as for primary hip replacement.

- Primary knee replacement

This involves replacement of the knee joint. Mobility before surgery becomes increasingly difficult and painful for the patient.

- Feet

This category covered a range of operations on repair or replacement of metatarsal joints.

- Spine discectomy

Patients tend to be in acute pain which affects physical mobility. A radiculogram or myelogram is always performed as a diagnostic technique before the recommendation of surgery. If indicated the disc is then repaired in surgery and loose bone fragments surrounding it removed.

- Carpal tunnel syndrome

This is caused by soft tissue injury or infection to the median nerve. It causes impairment, sensory loss, and a motor deficit. The operation involves dividing the flexor retinaculum under which the nerve passes.

- Dupuytren's contracture

This manifests as nodular thickening around the palm area, which cause the little finger and adjacent finger to contract inwards. Surgery involves releasing the contracture.

- Metacarpophalangeal joint replacement (MCP) The metacarpal phalange joints are damaged through arthritis, the joints become stiff or fixed and erode. The treatment involves the joints being surgically replaced by a prosthesis.

- Flexor tenosynovectomy

This is caused by rheumatoid arthritis invading and destroying the synovial linings of tendon sheathes. It causes pain and mechanical block and prevents the finger joints from flexing properly creating deformity of the interphalangeal joint. The operation corrects this by freeing and transferring tendons.

\section{Appendix II}

DERIVATION OF COSTS AND BENEFITS OVER TIME Costs

The baseline cost is derived from the extra contractual referral (ECR) price or the patient based costs adjusted by follow up visits.

Where revision of a prosthetic replacement occurs as a genuine complication of the host hospital (rather than failure of a joint replaced at another hospital or long term wear and tear), it is assumed that a revision occurs on average approximately five years after the initial joint was replaced.

The final cost figure for each procedure is therefore:

Baseline cost + (cost of revision $\times$ probability of revision) discounted by five years (assuming a $6 \%$ test discount rate) + (cost of complication $\times$ probability of complications) + (cost of readmissions $\times$ probabiity of readmissions).

or

$$
\begin{aligned}
\mathrm{C}=\mathrm{C}_{\mathrm{b}}+\left(\mathrm{C}_{\mathrm{r}} \times \operatorname{Pr}\right) 1 /(1+0.06)^{5}+ \\
\left(\mathrm{C}_{\mathrm{c}} \times \mathrm{P}_{\mathrm{c}}\right)+\left(\mathrm{C}_{\mathrm{ra}} \times \mathrm{P}_{\mathrm{ra}}\right)
\end{aligned}
$$

Where: $\mathrm{C}=$ total cost; $\mathrm{C}_{\mathrm{b}}=$ base line cost; $\mathrm{C}_{\mathrm{r}}=$ revision cost; $\mathrm{C}_{\mathrm{c}}=$ complication cost (excluding hospital admissions); $\mathrm{C}_{\mathrm{ra}}=$ cost of readmission (excluding readmission as a consequence of revision); $\mathrm{P}_{\mathrm{r}}=$ probability of revision; $\mathrm{P}_{\mathrm{c}}=$ probability of complication; $\mathrm{P}_{\mathrm{ra}}=$ probability of readmission.

\section{Benefits over time}

Benefit calculations are derived separately for the Rosser QALY and the EuroQol.

The base line benefit is the sum of the final outcome - initial outcome (by procedure)

$$
\mathrm{QL}=\Sigma \mathrm{QF}-\Sigma \mathrm{QI}
$$

Where: $\mathrm{QL}=$ quality of life or benefit in terms of QALYs; QI = initial QALY score; QF = final QALY Score.

$\mathrm{QL}$ is presented as an average for each procedure hence the QALY score by procedure (QT) is:

$$
\mathrm{QT}=\Sigma \mathrm{QL} / \mathrm{n}
$$

Where $\mathrm{n}=$ sample size

Life expectancy to death (LYD) for each procedure $=$ average years life left until death males $\times \%$ of males in the sample + average years life left until death in females $\times \%$ of females in the sample.

$\mathrm{TPL}=$ total prosthesis life where:

$$
\mathrm{TPL}=\mathrm{PL}_{\mathrm{ND}}+\mathrm{PL}_{\mathrm{D}}
$$

$\mathrm{PL}_{\mathrm{ND}}=$ the prosthesis life before any substantial decay occurs in the prostheses.

$P L_{D}=$ additional years of prosthesis life after the prosthesis has started to decay.

$1 / \mathrm{D}=$ the decay rate of the prosthesis.

$\mathrm{m}=$ mortality rate for the individual hospital.

$\mathrm{R}=$ reoccurrence rate.

$L D_{R}=$ lost years of benefit from point of reoccurrence.

When calculating total benefit in QALY calculations, percentage that benefit would normally need to be built into the QALY calculation, however in this sample the average benefit figure already takes into account the percentage that benefit for each procedure. 
Total benefit over life is:

$$
\begin{aligned}
& \mathrm{QT}_{\text {TOTAL }}=\mathrm{QT}\left(\mathrm{PL}_{\mathrm{ND}}+\mathrm{PL}_{\mathrm{D}} 1 / \mathrm{D}(\mathrm{LYD}-\right. \\
& \left.\left.\mathrm{PL}_{\mathrm{ND}}\right)\right)-\% \mathrm{~m}(\mathrm{QI})-\% \mathrm{R}\left(\Sigma \mathrm{LYD}_{\mathrm{R}}(\mathrm{QL})\right) \\
& \text { Where } \mathrm{LYD}>\mathrm{PL}_{\mathrm{ND}} .
\end{aligned}
$$

If $\mathrm{LYD}<\mathrm{PL}_{\mathrm{ND}}$ or no prosthesis is involved:

$$
\mathrm{QT}_{\mathrm{TOTAL}}=\mathrm{QT}(\mathrm{LYD})-\% \mathrm{~m}(\mathrm{QI})-
$$$$
\% \mathrm{R} \Sigma\left(\left(\mathrm{LYD}_{\mathrm{R}}(\mathrm{QT})\right)\right.
$$

The authors would like to thank the staff and patients at Wrightington Hospital for their cooperation in this study and Professor Alan Williams and Dr Claire Gudex at the Centre for Health Economics, University of York, for the inspiration for this work.

1 Wilcock GK. A comparison of total hip replacement in patients aged 69 years or less and 70 years or over. Gerontology 1981;27:85-8.

2 Wroblewski BM. Charnley low friction arthroplasty in patients under the age of 40 years. In: Sevastik J, Goldie $\mathrm{I}$, eds. The young patient with degenerative hip disease. Stockholm: Almqvist \& Wiksell International, 1985.

3 Walker SJ, Sharma P, Parr N, Cavendish ME. The longterm results of the Liverpool mark II knee prosthesis. $f$ Bone foint Surg 1986;68:111-16.

4 Eftekhar NS. Long-term results of cemented total hip arthroplasty. Clin Orthop 1987;225:207-217.

5 Daellenbach HG, Gillespie WJ, Daellenbach US. Economic appraisal of new technology in the absence of survival data - the case of total hip replacement. Soc Sci Med 1990; data - the case of

6 Kind P, Rosser R, Williams A. Valuation of quality of life: some psychometric evidence. In: Jones-Lee MW. The value of life and safety. London: North Holland Publishing Co, 1982

7 Gudex C, Kind P. The QALY Toolkit. Discussion paper 76. York: Centre for Health Economics, University of York, 1987.

8 EuroQol Group. EuroQol - a new facility for the measurement of health-related quality of life. Health Policy 1990; 16:199-208.

9 Yates J. Why are we waiting? Oxford. Oxford University Press, 1987.

10 Gudex C, Williams A, Jourdan M, Mason R, Maynard J O'Flynn $\mathrm{R}$, Rendall M. Prioritising waiting lists. Health Trends $1990 ; 22(3): 103-8$.

11 Williams A. Health economics, priority setting and medical ethics: implications for multiple sclerosis. Discussion Paper 71. York: Centre for Health Economics. University of York, 1990.

12 EuroQol Group. EuroQol - a new facility for the measurement of health-related quality of life. Health Policy 1990 16:199-208.

13 Brooks RG. EuroQol: health-related quality of life measurement. Results of the Swedish questionnaire exercise. Health Policy 1991;18:37-48.

14 Nord E. EuroQol: health-related quality of life measurement. Valuations of health states by the general public in ment. Valuations of health states by the

15 Essink-Bot ML, Bonsel GJ, van der Mass PJ. Valuation of health states by the general public: feasibility of of health states by the general public: feasibility of standardized meas

16 Kind P. Measuring valuations for health states: a survey of patients in general practice. Discussion Paper 76. York: Centre for Health Economics. University of York, 1990

17 Kind P, Rosser R, Williams A. Valuation of quality of life: some psychometric evidence. In: Jones-Lee MW ed. The value of the life of safety. North Holland Publishing Co. 1982.

18 Hadorn DC. Setting health care priorities in Oregon. Cost effectiveness meets the rule of rescue. $\mathcal{F A M A} 265(17)$ $2218-25$.

19 Dixon J, Welch HG. Priority setting: lesson from Oregon. Lancet 1991;337:891-4.

20 Williams A. Measuring quality of life: a comment. Sociology 1987;21(4):565-66. 